\title{
Hashimoto's thyroiditis presenting as acute psychosis with religious delusion: a case report
}

\author{
A Rizvi, F Shaan, N Fatima
}

\section{Abstract}

Hashimoto's thyroiditis is the most common cause of hypothyroidism which can have psychiatric manifestation at first presentation which at times, may be so striking that patients are first diagnosed with a primary psychiatric disorder. We describe a case of 35 year old female patient who presented with acute psychosis with religious themed persecutory delusion. Further evaluation revealed a diagnosis of Hashimoto's thyroiditis. Patient was started on thyroxin and olanzapine to which she responded and her psychosis resolved in two weeks. Olanzapine was reduced and stopped and, her thyroid function test at the end of three month was within normal range

Key words: Hashimoto's thyroiditis, acute psychosis, religion themed delusion

SL J Psychiatry 2017; 8(2): 29-30

\section{Introduction}

Thyroid diseases are, arguably, among the commonest endocrine disorders worldwide and the Indian subcontinent is no exception to this. Kochupillai et al. in 2000 reported the prevalence of thyroid disorders in India to be around 42 million (1). There has been a gradual decline in the cases of iodine deficiency in India and now Hashimoto's thyroiditis is probably the commonest cause of goiter (2,3). Hypothyroidism especially in women of child bearing age of majority of whom remain undiagnosed (4).

Hypothyroidism has been linked to depression and acute psychosis as early as in 1800. In 1949, Asher coined the term "myxedematous madness" to identify the psychotic manifestations of hypothyroidism, reporting 14 cases of psychosis with hypothyroidism $(5,6)$. Recent literature point towards a possible pathophysiological mechanism contributing to the coexistence of the two disorders. The hypothyroid patient may, among the earliest and most prominent signs or symptoms, report psychiatric symptoms. At times, the psychiatric presentation may be so striking that patients are first diagnosed with a primary psychiatric disturbance rather than hypothyroidism $(5,7)$.

We present an interesting case report of 35-year-old female who came with acute psychosis and without previous history of thyroid dysfunction. The case also demonstrates the delay in diagnosis that happens when the content of delusion has religious theme.

\section{Case}

Patient "Mrs. M," a 35 years-old illiterate Hindu, married woman from a small village in north India having three children, presented to psychiatric outpatient department with chief complaints of insomnia, irritability, and fearfulness which started 15 days back. There was a noticeable change in her behavior as she started doing "Puja" (worship) to ward off "Nazar" (evil eye) with the blessing of "Mata Kali" (Hindu Goddess). Her husband tried to stop her after which she became very fearful for her life as well as the life of her two sons. She would cry loudly and say that Mata Kali is very angry with her and Mata Kali would destroy her family as well as the entire village. She stopped sleeping at night performing Puja and chanting verses. When her neighbors came to know about her condition they started worshipping her as the reincarnation of Hindu Goddess Kali. Slowly her condition worsened and she stopped taking food and water suspecting it of being poisoned and started beating all people who would near her. When her condition further deteriorated and she became dehydrated she was brought to psychiatric OPD for consultation. The patient had no history of any previous psychiatric illness, addiction, or any psychoactive substance abuse. There was no history of any previous medical illness or comorbidity as well as no family history of any psychiatric illness.

When the patient was evaluated in the Outpatient Department she was disheveled, dehydrated, uncooperative and irritable. Persecutory delusion that goddess kali is preparing to kill her, her family and her entire village as well as auditory hallucination were 
present. On the day of hospitalization patient was started on olanzapine $10 \mathrm{mg}$ stat to calm her down and blood samples were collected for biochemical tests, thyroid function tests, liver function tests, renal functions tests and vitamin B12. Tests were reported as fT3 $=2.41 \mathrm{pg} / \mathrm{mL}$

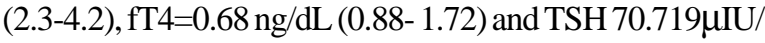
$\mathrm{mL}(0.63-4.82)$ while other tests were within the normal range. Internal medicine consultation was done, and ultrasound scan of thyroid revealed diffuse heterogeneity in thyroid parenchyma. Anti-thyroid peroxidase (AntiTPO) level was found out to be $122.18 \mathrm{IU} / \mathrm{mL}$ (0-35) while Thyroglobulin level was within normal limits. Hence a diagnosis of Hashimoto thyroiditis was reached.

On day 2 of hospitalization treatment was planned as thyroxin $75 \mu \mathrm{gm} /$ day and olanzapine was increased to $20 \mathrm{mg} /$ day. From 4th day onwards she started to show improvement in her activity. The psychotic features were completely recovered on the $12^{\text {th }}$ day. The olanzapine dose was reduced to $15 \mathrm{mg}$ daily and patient was discharged with improvement on the $15^{\text {th }}$ day. She was reviewed a week later. Her functioning was significantly improved and there were no psychopathology. Olanzapine was further reduced to $5 \mathrm{mg}$ daily and stopped in the next visit and she was attached to medicine OPD for future follow-up. She was interviewed 3 months later and there was no psychopathology, and TFT results were within normal limits $\mathrm{fT} 3=2.71 \mathrm{pg} / \mathrm{mL}(2.3-4.2)$, $\mathrm{fT} 4=0.79 \mathrm{ng} / \mathrm{dL}(0.88-1.72)$ and TSH $3.65 \mu \mathrm{IU} / \mathrm{mL}$ (0.63-4.82).

\section{Discussion}

Acute psychosis could be one of the early manifestation of the Hashimoto's thyroiditis. Behavioral changes may occur in the absence of the classical physical signs and symptoms of the disorder. As a result, it is imperative to remember that many patients presenting with psychiatric disorders may have alterations in endocrine function and are often misdiagnosed as functional psychiatric disorders, rather than a psychiatric disorder due to a general medical condition. This confusion leads to delayed treatment and a high likelihood of increased morbidity. Hashimoto's thyroiditis might be linked to psychotic phenomenon independent of its hormonal status with autoimmunity as a possible etiology, similar to the case of Hashimoto's encephalitis (8). Treatment of this condition is controversial. Whether thyroid hormone supplementation alone is adequate or it should be combined with antipsychotic. We treated the patient with a combination of thyroxin and antipsychotic and reduced the dose of antipsychotic medication and stopped within three weeks.

Another interesting aspect of the case was the delay in diagnosis due to the fact that content of delusion and hallucination was having a religious theme. Religiously themed delusion and hallucination believed to be very common (9). A unique problem in religiously themed psychopathology is the acceptability by the society which causes delay in bringing the patient to mental health services. This is further compounded by the phenomenon of occurrence of hallucination with the religious theme in normal individual raising the age old question of where to draw the line between normal and abnormal. Nevertheless it seem reasonable to believe that if patient demonstrate a deterioration in his/her general functioning and self-care, that should be treated as pathological and brought to the attention of mental health professionals for assessment no matter what the theme of psychopathology is.

\section{Disclosure Statement}

None declared

A Rizvi, F Shaan, Department of Psychiatry, Jawaharlal Nehru Medical College, Aligarh Muslim University, India

N Fatima, Department of Social Work, Jamia Milia Islamia University, New Delhi, India.

\section{Corresponding author: A Rizvi}

Email: abidrizvi021@gmail.com

http://orcid.org/0000-0002-4105-596X

\section{References}

1. Kochupillai N. Clinical endocrinology in India. Curr Sci 2000; 79(8): 1061-7.

2. World Health Organization (WHO). Iodine status worldwide: WHO global database on iodine deficiency disorders. Geneva: WHO, 2004.

3. Velayutham K, Selvan SS, Unnikrishnan AG. Prevalence of thyroid dysfunction among young females in a South Indian population. Indian J Endocrinol Metab 2015; 19(6): 781-4.

4. Sanyal D. Spectrum of Hashimoto's thyroiditis: Clinical, biochemical \& cytomorphologic profile. Indian J Med Res 2014; 140(6): 710-2.

5. Heinrich TW, Grahm G. Hypothyroidism presenting as psychosis: myxedema madness revisited. Prim Care Companion J Clin Psychiatry 2003; 5(6): 260-66.

6. Rao AC, Bhat VK, Kini S. Myxoedema Presenting With Psychosis. Indian J psychiatry 1990; 32(3): 287.

7. Boillet D, Szoke A. Psychiatric manifestations as the only clinical sign of hypothyroidism. Apropos of a case. Encephale 1998; 24(1): 65-8.

8. Haider AS, Alam M, Adetutu E, Thakur R, Gottlich C, DeBacker DL, Marks L. Autoimmune Schizophrenia? Psychiatric Manifestations of Hashimoto's Encephalitis. Cureus 2016; 5; 8(7): e672.

9. Cook CC. Religious psychopathology: The prevalence of religious content of delusions and hallucinations in mental disorder Int J Soc Psychiatry 2015; 61(4): 404-25. 